\title{
The Changing Ecology of IT Management: Cross-Disciplinary Explorations of Context and Content
}

\author{
Elia V. Chepaitis \\ Fairfield University, Fairfield, CT, USA \\ echepaitis@mail.fairfietd.edu
}

\begin{abstract}
In the past decade, the context of Information Technology (IT) management changed in seminal areas: the circle of players, the tools, the emergence of Internet technologies, the evolution of information societies and digital economies, and critical questions of ethics and equity.

These seismic changes can be captured if corresponding shifts occur in the content and context of IT education. A shift in context alters courses, methods, and materials but also the curriculum itself. The author identifies a variety of projects that immerse students in the altered ecologies of IT management and of IT education. The paper describes one of these projects--a student-authored proposal for a textbook on international information systems.
\end{abstract}

Keywords: international, student-authored, ecology, soft factors, infrastructure, cross-disciplinary, socioeconomic, textbook proposal

\section{Introduction: The Altered Ecology of IT Education}

In the past decade, the context within which Information Technology (IT) is managed changed in seminal areas, including the circle of players, the tools, the emergence of Internet technologies, the evolution of information societies and digital economies, and critical questions of ethics and equity. The author redesigned courses to help students benefit from the organic relationships and dynamic balances that represent a new ecology of IT management and IT education.

These courses seek answers to the query, "What are the important questions in IT in 2002?" and focus on motile components and spreading parameters. When they play an actual role in curriculum development, teaching, or materials selection, students are excited to be where the action is. IT emerges as an intellectual and operational frontier, in which different stakeholders identify different questions as critical, and in which issues and challenges change dramatically within the space a few years.

This paper presents strategies and tactics that empower student sleuths to conduct real-time investigations of IT management in changing environments, and to create dynamic educational traditions. Students both drive the course and also bequeath a legacy of recommendations and materials for future classes. Collections of student-authored projects create synergies within the classroom and, hopefully, promote lifelong learning and habits of independent analysis.

Material published as part of these proceedings, either on-line or in print, is copyrighted by Informing Science. Permission to make digital or paper copy of part or all of these works for personal or classroom use is granted without fee provided that the copies are not made or distributed for profit or commercial advantage AND that copies 1) bear this notice in full and 2) give the full citation on the first page. It is permissible to abstract these works so long as credit is given. To copy in all other cases or to republish or to post on a server or to redistribute to lists requires specific permission from the publisher atPublisher@intormingscience.org

\section{Motives, Methods, and Out- comes Using Student Sleuths}

The author challenges students to unearth, analyze and discuss the most important questions in ICTs (Information and Communication Technologies) in a variety of courses: systems analysis and design, systems in organizations, international information 


\section{Changing Ecology of IT Management}

systems, international IT management, and the rise of the information economies. Teams design textbooks, select materials and textbooks for use in introductory IT courses, and identify the most important questions in topical areas--at the moment.

Evidence-based field studies and team projects immerse students within the context of IT management, and help investigators to appreciate problems of balance between technical and managerial skills, and changing information challenges and IT relationships.

Naturally, the Internet is essential to real-time investigation in these courses, both as a tool and as a subject of investigation. Evidence-based investigations occasionally enable student teams to contrast their research with dated, narrowly focused cases which neglect socioeconomic data, history, and geopolitical realities without which soft factors in IT cannot be grasped.

Table 1 contains a list of tasks and projects routinely completed in an academic year by student teams. Syllabi must be changed, catalogs must use student input, textbooks must actually be chosen and examinations administered that have a heavy degree of student authorship. Student textbook proposals must be forwarded to editors who are truly interested in guidelines for actual publication.

\begin{tabular}{|} 
A Novel Approach to Systems Analysis and Design \\
The Most Important Questions at the End of Each Week \\
Student-Authored Assessment Questionnaires \\
Student-Authored Course Catalog Descriptions \\
Student-Authored Textbook Proposals \\
Student-Authored Proposals for Quizzes and Exams \\
Student Proposals for Syllabi \\
Foreign Exchanges of Student Projects with Feedback and Reciprocity \\
Student Textbook Selection for Introductory Courses \\
Student-Invented Board Games \\
Students Actors Posing as Guest Lecturers: the class as Dramatis Personae \\
Students as Editors, Discussants, Reviewers and Graders \\
Table 1. The Student Sleuths' Tool Box
\end{tabular}

\section{A New Context: the IT Educator as Facilitator, Messenger, and Diplomat}

Within this altered ecology, the professor must be facilitator for three reasons: time limitations within standard semester lengths, the ability to secure and develop resources (team study rooms, videos materials, software,) before the course, to scour recent publications, contacts, and cases for excellent selections. Furthermore, during the course, the professor is sometimes a "gopher", providing teams with expertise, editorial assistance, references, material resources, and, occasionally, assurances of secrecy and selfgovernance. Finally, the instructor must use political and diplomatic leverage to deliver the value developed in projects--proposals, games, assessments, course changes--beyond the classroom and into future semesters.

For example, in 1992, 1995, and 1997, students in systems analysis and design prepared rich and evocative research projects for foreign students who would take systems analysis and design the following year 
(Chepaitis, 1997). The author had three Fulbright fellowships in the 1990s, and arrived in Eastern Europe, Eurasia, and North Africa equipped with student-to-student presentations from her home institution. Not only foreign students, but also colleagues in host institutions abroad, benefited from the thoughtful content, arresting formats, and thoroughness to detail in these gifts. In turn, students in the host country developed and sent projects back to their counterparts in the United States-completing a rich decade-long exchange cycle. Across cultures, across academic traditions, and within multiple disciplines, student teams realized that their work was serious and valued.

\section{The Student-Authored Textbook Proposal}

International Information Systems is an ideal course in which students can develop a textbook proposal. First, there are no recent textbooks in international information systems. Second, the course itself requires justification (Table 2), and this status provokes discussion. Third, coupling the study of current international business environments with IT management issues, the course requires team-based, multidisciplinary investigations of dynamic challenges and issues.

The class utilized the debate about the value and focus of International Information Systems as a springboard for a lively course. Students conducted a systematic investigation of related textbooks and readings, existing proposals, and publishers' expectations. Teams worked together for ten weeks of continuous brainstorming to develop a framework in which to position and present the most important questions in International Information Systems.

In the past decade International Information Systems (IIS) has been accepted broadly as a component of the IT curriculum (Jenkins, 1990). IIS is offered either as a stand-alone course or as a set of integrated topics in non-IIS courses. Yet IIS has not matured as much as additions such as e-commerce, ethics, or object-oriented programming have. The ongoing debate on the inclusion of IIS is not heated, but there is a lack of agreement in several key areas: the content of teaching materials, the selection of topics, the degree to which concept should corporate theory from other disciplines, the value of an international classification for global applications, and the degree to which socio-economic issues should be covered. Although IIS has not been the topic of heated debate, acceptance has been piecemeal and lukewarm (1997, Deans and Loch). Educators have not invested heavily in IIS, and have not yet developed and maintained adequate teaching materials.

Undeniably, even with the lack of materials, theory, and materials, IIS can be taught effectively, with an enormous amount of range and creativity. The author decided to challenge students to evaluate the leading materials used in IIS courses, to identify the most important questions in IIS, and to produce and justify a detailed outline for a textbook. In short, we used the debate about IIS as a springboard for a lively course. The students conducted a systematic and critical analysis of textbooks and readings, and we put our heads together for ten weeks of continuous brainstorming, quality research, and a rigorous analysis of the field. 


\section{Changing Ecology of IT Management}

1. the lack of consensus among both academics on the content of the course;
2. the lack of consensus among academics about the need for a stand-alone course and about the
amount of time which should be devoted to IIS in the rest of the IS curriculum;
3. the identification of varied priorities and needs by IT managers in foreign environments and
global enterprises;
4. the difficulty of developing IIS because of a lack of language skills, research abroad, or foreign
work experiences, in contrast with extensive and ongoing practical experience in other new mod-
ules, such as ethics, object oriented programming, or the Internet (Chepaitis, 1997);
5.a difference of opinion about whether technical aspects of the course have been overemphasized
which endures and possibly has broadened since the inclusion of the Internet in the curriculum;
6. a difference of opinion about which technical aspects of IIS should be included in view of the
emergence of the computer as an effective and economical global communication tool, rather
than a computation device;
7. the difficulty of including new courses and new components in the expanding IT curriculum;
8. the lack of a robust body of IIS theory;
9. the reluctance of administrators to support an expansion of IIS in the midst of ongoing debates
on upgraded IT facilities, resource sharing, curriculum integration and duplication of courses, and
cost justification; and perhaps, most importantly,
10. the changing nature of IIS because of ongoing change in global markets, especially in services.

Table 2. IIS: An Ideal Course for Student-Authored Textbook proposals

\section{Course Focus}

How can we present a course without materials, theory, or a rigorous justification? The author presented this problem to students as the theme of a seminar on IIS. This seminar is cross-listed as an elective for majors and minors in both information systems and international studies, but the vast majority of students who take this course are information systems majors. The students were asked throughout the course to take a critical approach to the subject matter, and to keep in mind the one irreverent question we ask about every course in IS: "So what?" What is the purpose of this course, why are our investigations significant?

The challenge was to present IIS as a frontier, an area of discovery, a field in need of definition. The author sought to capitalize not only on the ambiguous position of IIS, but also on the composition of the class: a balanced mixture of IT and business majors and International Studies majors.

The students were presented with a task: to write a textbook proposal for Prentice Hall. Sample proposals for other textbooks, and a tentative outline for IIS were distributed at the first class, and students were invited to rip the outline apart and write the book, which they entitled Going Global: Information Systems and Competitive Advantage in the Global Marketplace.

\section{Course Requirements}

The syllabus at first glance looked not only traditional but heavily structured. They were assigned a book of readings and presented with the questions for a midterm and final exam (Fig.1). Students decided what the grading for the course would be based on, and the point distribution was added to the syllabus. They also had to decide how the weekly sessions should be organized and evaluated during their ten week leadership. We agreed to two rules: "Be prepared, and make it interesting." The author invited students to decide on the distribution of points for grading, and to choose what readings the class would discuss next. 


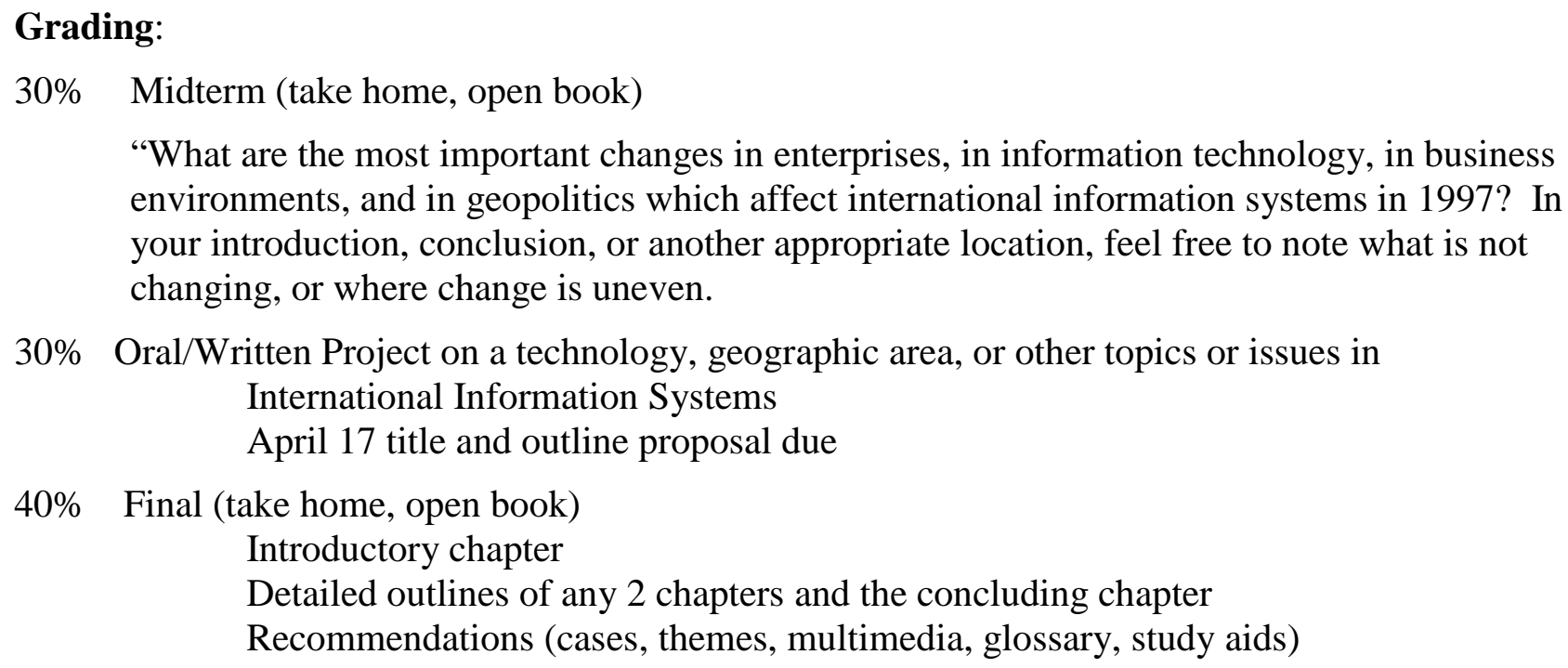

30\% Oral/Written Project on a technology, geographic area, or other topics or issues in

International Information Systems

April 17 title and outline proposal due

$40 \%$ Final (take home, open book)

Introductory chapter

Detailed outlines of any 2 chapters and the concluding chapter

Recommendations (cases, themes, multimedia, glossary, study aids)

Fig. 1 Course Grading

\section{Learning Methods: A Syllabus, a Task, and Student -Generated Rules}

Students were presented with a syllabus with "We're Going to Write the Book!" centered on the top line. The exhortation was not just a description of the major thrust of the course, but also a reference to the triumphant exclamation by George C. Scott in the movie Patton: "I wrote the book...!" Hopefully, the expression suggested a feeling of achievement and adventure.

They also were given the essay question for a Midterm exam, the general requirements for an independent project, and the format for the Final exam, the textbook proposal for IIS. The proposal included three components: an introduction and a conclusion of no less than ten pages; an outline with detailed subheadings; and a textbook title, cover design, bibliography of cases, and other materials such as graphics which student-authors might choose to include.

The syllabus included an invitation for take over the class after the first five weeks of the semester, which were instructor's responsibility. In those weeks we surveyed germane information technologies and paradigm shifts in the global marketplace, and we also scanned textbooks in International Marketing, International Finance, and International Management to see if a textbook in IIS could use a similar format. In International Management and International Marketing, for example, often tables of contents resembled the basic marketing and management texts, with international differences highlighted and appropriate examples and cases included.

The students found that it was not appropriate to adopt the same structure as a main-stream IT textbook, to give an international application to domestic topics in a very simple and straightforward manner. The criticisms were: too much overlap with other courses and too little attention to many seminal IIS topics and issues that just didn't fit in a standard rubric. By the third week, we had produced a Table of Contents which hung together loosely, but would be worked on and amended over the next ten weeks (Figure 2). The first three chapters clearly mirrored the material covered in class lectures from the first three weeks, but Chapters IV through XI were thrown together rather hastily by week 8, and were refined until week 13 (Figure 3). The students ran the course for the last 10 weeks of the semester, with the exception of the Midterm and Final. They were invited to make their own rules - to get the job done effectively and equitably, and were requested to teach the instructor as well as each other. They could ask for research assistance, contacts with authors, and editorial advice anytime, and a liaison with a textbook editor was arranged. Everyone involved learned to listen, including the instructor. The methodology used in this could be called learning rather than teaching. 


\begin{tabular}{|c|c|}
\hline \multicolumn{2}{|r|}{ First Draft: Table of Contents } \\
\hline Chapter 1 & Introduction: The Global Marketplace and International Information Systems \\
\hline Chapter 2 & The Changing International Business Environment: Paradigm Shifts \\
\hline Chapter 3 & $\begin{array}{l}\text { Changing Information Systems: Internet Technologies, Wireless, } \\
\text { Open, Integrated, Extended Communication Systems }\end{array}$ \\
\hline Chapter 4 & $\begin{array}{l}\text { Issues and Trends in Information Resource Management Goals: } \\
\text { Efficiency, Effectiveness, Competitive and Strategic Advantage }\end{array}$ \\
\hline Chapter 5 & $\begin{array}{l}\text { International Information Resources and Needs: Patterns of } \\
\text { Economic Development, Salient Regional Differences, National } \\
\text { Priorities }\end{array}$ \\
\hline Chapter 6 & $\begin{array}{l}\text { International Management and International Information Systems: } \\
\text { with cases }\end{array}$ \\
\hline Chapter 7 & $\begin{array}{l}\text { International Marketing and International Information Systems: } \\
\text { with cases }\end{array}$ \\
\hline Chapter 8 & $\begin{array}{l}\text { International Finance and International Information Systems: } \\
\text { with cases }\end{array}$ \\
\hline Chapter 9 & $\begin{array}{l}\text { International Accounting and International Information Systems: } \\
\text { with cases }\end{array}$ \\
\hline Chapter 10 & Information Technologies and International Systems Management \\
\hline Chapter 11 & International Information Management Trends and Challenges \\
\hline & Figure 2. Table of Contents \\
\hline
\end{tabular}

In the first class, we was decided that weekly attendance was mandatory, and that there was so much work to be done, that the instructor be assigned tasks and reports also. After the five introductory sessions, the students decided that they would rotate and lead all class discussions except for the first twenty minutes of class when the instructor would distribute materials, make announcements, ask procedural questions, or offer assistance.

The syllabus at first glance looked not only traditional but heavily structured. Students were assigned a book of readings and presented with the questions for a midterm and final exam (Fig.1). They decided what the grading for the course would be based on, and the point distribution was added to the syllabus. The class also had to decide how the weekly sessions should be improved and evaluated during their ten week leadership.

\section{Student Response}

The students initially read the syllabus with a mixture of bewilderment, skepticism, and concern. Two of the four international studies majors withdrew from the course, leaving us with a class of eight. However, in the first three weeks, as students became familiar with the material, they became wildly enthusiastic, and we achieved a good degree of class participation. Cases, videos, and data on competition and the changing global marketplace blended neatly with theory on open, integrated, and extended systems.

The spark which really warmed the class was the first IIS textbook outline, however. Once the students had an outline in hand, the class had a center, the "Book" (henceforth capitalized); they then were able more easily to articulate complex problems and concepts. The weekly discussion on the division of labor, known as "What to do and who to do it?" became more focused after the Midterm, but it was unfocused 
and unproductive in the first twenty minutes of the first weeks of student-run sessions. However, "What to do and who to do it" became less chaotic, and the quality of the discussions of common readings, the status reports on individual projects, and the Book was first rate throughout the semester.

\section{Outcomes}

Students identified the major questions in IIS, which was the purpose of the course, and they learned IT within cross disciplinary perspectives. Six areas were relatively novel to them:

1. multidisciplinary research and teaching;

2. international socioeconomic issues;

3. changing global business needs and ranges of shifting relationships;

4. the impact of varied value systems upon IS ethics, and of discontinuities in socio-economic infrastructures (Kantrow, 1985);

5. resource management challenges in foreign environments;

6. varied information technology infrastructures;

7. a projection of the socio-economic impacts of emerging technologies, such as wireless telecommunications.

The focus of the proposal was primarily competitive advantage through information systems, which was reflected in their title. They covered an enormous amount of material, especially about international business environments and constraints, but learned very little in depth, especially in the area of information technology. The material presented in the first weeks of the course was absorbed and used to advantage, but students had little time left to scout around for other materials and use resources such s the Internet. Also, the title of the proposed book was written in haste with little discussion about whether it squared with the topics and themes agreed upon in the Table of Contents.

The decision by students to diverge from the syllabus and to collaborate on one Table of Contents and one title, and then develop individual projects was pivotal to the success of this course. The student evaluations which the instructor received the following fall rated this course as excellent, but offered one salient criticism: the materials were occasionally dated and also could have been better coordinated.

\section{Teamsmanship, Responsibility, and Confidence}

All the participants, including the instructor, worked hard and honestly together on this project and cooperated in this frankly experimental effort. As discussed above, listening was both an outcome and a method, and listening skills improved steadily through the semester. The students rejected measurements to evaluate contributions weekly, and that facilitated creativity and frank exchanges.

Information systems majors and minors dominated the course until the last weeks of the semester, however. This was not because the course very technical, but possibly because the international studies students had less experience working with teams and were relatively unfamiliar with the terminology as well as group dynamics. The immersion method of learning worked well, but it took about a month for students to run the class constructively, and for trust to develop in an class which may have seemed bizarre initially.

Learning that it was all right, and necessary, to make mistakes in this common enterprise was liberating and constructive. Students accepted responsibility bravely in January and February, and took possession of the class in March and April. They mentioned several times that they were having fun. 


\section{Changing Ecology of IT Management}

\section{What the Instructor Learned}

The proposals and the outlines for the text, Going Global: Information Systems and Competitive Advantage in the Global Marketplace, surpassed the instructor's expectations (Figure 3). However, the course would be improved if these measures were taken:

1. eliminate the individual project which took too much time and did not add significant depth to the course;

2. participate extensively or not at all in the first student-driven session which was chaotic;

3. prepare a more current varied group of readings, videos, and cases, and Internet searches;

4. push the deadlines forward; and, most importantly,

5. require that the students produce a joint proposal of fifty or sixty pages encompassing several chapters, rather than individual deliverables.

\section{Final Table of Contents}

Chapter 1 The Global Marketplace and International Information Systems: IT and The Movement toward Open, Integrated, and Extended Markets

Chapter 2 Soft Factors in International Business Environments: Government Regulations, Socio-Economic Factors, and Cultural Constraints

Chapter 3 Emerging Technologies for Open, Integrated, and Extended Systems: E-Commerce, Wireless, Satellite-Based Services

Chapter 4 Issues and Trend in Information Resource Management: Efficiency, Effectiveness, Competitive and Strategic Advantage, and Privatization

Chapter 5 International Information Resources and Needs:

Patterns of Economic Development, Salient Regional Differences, National Priorities, Security Issues

Chapter 6 Changes in Telecommunications:

Software Development, Deregulation, and Cases in International Management, Marketing, Finance, and Accounting

Chapter 7 International Information Systems Management:

Trends and Challenges

Chapter 8 Conclusion

Figure 3: Final Table of Contents 


\section{Conclusion}

In this seminar, students experienced engaged in multidisciplinary research and teaching, and viewed IIS from a number of varied socioeconomic perspectives. They investigated current challenges such as the conversion to the Euro, developed projections of changing global business needs, and postulated ranges of appropriate solutions. In addition, they discussed at length the impact of soft factors, especially value systems, upon IT effectiveness and ethics. Most of all, we learned what we did not, and often could not, know.

Significant attention was devoted to the broad range of different IT infrastructures, their ownership, and the regulatory environment affecting the Internet and E-Commerce

Finally, by analyzing an academic frontier through writers' eyes, students improved their conceptual, organizational, and interpersonal skills, and gained significant confidence in their intellectual capabilities.

\section{References}

Chepaitis, E. (1997).“Taking the show on the Road: the multiple rewards of teaching information systems abroad.” Proceedings: International Academy for Information Management. Atlanta, GA.

Chepaitis, E. Deans, C., and Loch, K. (1997) "Is there a difference or who's doing what? A comparison of AACSB Accredited and Non-Accredited Schools' Internationalization of the Information Systems curriculum. Proceedings: International Academy for Information Management. Atlanta, GA.

Jenkins, A. M. ed. Research Issues in Information Systems: An Agenda for the 1990s. W. C. Brown, 1990.

Kantrow, A. M. ed. (1985) "Why history matters to managers." Harvard Business Review. 86(1), 81-88.

\section{Biography}

Elia Chepaitis is an associate professor of information systems at Fairfield University with interests in international information systems and economic development, information infrastructures and information quality, and information and communication technologies for the visually impaired utilizing an easy-touse alternative to Braille. 